\title{
How to overcome lockdown: selective isolation versus contact tracing
}

\author{
Lucie White (1) , Philippe van Basshuysen
}

\begin{abstract}
At this stage of the COVID-19 pandemic, two policy aims are imperative: avoiding the need for a general lockdown of the population, with all its economic, social and health costs, and preventing the healthcare system from being overwhelmed by the unchecked spread of infection. Achieving these two aims requires the consideration of unpalatable measures. Julian Savulescu and James Cameron argue that mandatory isolation of the elderly is justified under these circumstances, as they are at increased risk of becoming severely ill from COVID-19, and are thus likely to put disproportionate strain on limited healthcare resources. However, their arguments for this strategy are contingent on the lack of viable alternatives. We suggest that there is a possible alternative: a mandatory, centralised contact-tracing app. We argue that this strategy is ethically preferable to the selective isolation of the elderly, because it does not target members of a certain group, relying instead on the movements of each individual, and because it avoids the extended isolation of certain members of the society. Although this type of contact-tracing app has its drawbacks, we contend that this measure warrants serious consideration.
\end{abstract}

In light of the COVID-19 pandemic, policies that would normally be considered repugnant are becoming serious options. One such policy is to selectively isolate the elderly, due to their increased risk of becoming severely ill from COVID-19, and thus the disproportionate strain they are likely to put on limited healthcare resources. Julian Savulescu and James Cameron argue that, in order to lift general lockdowns, mandatory isolation of the elderly should be imposed. ${ }^{1}$ They contend that isolating the elderly in this way is ethically permissible because it is less coercive than locking down the entire population until herd immunity is achieved, or an effective treatment or vaccination is developed.

Institut für Philosophie, Leibniz Universität Hannover, Hannover, Niedersachsen, Germany

Correspondence to Dr Lucie White, Institut für Philosophie, Leibniz Universität Hannover, Hannover, Niedersachsen, Germany;

lucie.white@philos.uni-hannover.de
In making their arguments for a selective isolation of the elderly, however, Savulescu and Cameron fail to pay adequate attention to other potentially viable alternatives. The ethical legitimacy of a selective isolation policy, according to Savulescu and Cameron, is contingent on the viability of other alternatives, specifically alternatives that can more effectively target proxies for risk of infection or severe illness, and that lead to less overall interference with liberty. There is one such potential alternative: an effective contact-tracing app.

Savulescu and Cameron briefly consider and discard the possibility of a contact-tracing app as an alternative to a selective isolation, partially because widespread testing will be needed to make sure that the system is not flooded with false positives. They seem to have in mind a centralised system here, in which app users can be identified by the relevant government agency. Under this system, users could immediately report any symptoms on the app, allowing for an immediate temporary quarantine of all their close contacts. In order to identify and correct for inevitable false positives through false alarms or malicious reports, reports must be followed up by testing, and contacts brought quickly out of quarantine where reports are established as erroneous. There is evidence to suggest that such a centralised, appbased system is the only contact-tracing system that allows for rapid enough action to prevent a second lockdown (as opposed to purely manual contact tracing, or a decentralised app-based system, where public health agencies have no access to the details of the infected, and thus, to avoid false positives, reporting can only take place after a confirmed test, leading to a lag which will result in significantly more infections). ${ }^{2}$ Savulescu and Cameron are right to note that this centralised system will only function with sufficient testing capacity. However, it appears that the selective isolation of the elderly might require an even higher testing capacity, ${ }^{23}$ as it will only function efficiently if caregivers are frequently tested (as often as daily), with quick testing turnaround. ${ }^{3}$ This might be thought to be borne out by the situation in Sweden, which focused on limiting social contact of those over $70^{4}$, but where over $90 \%$ of those who died (as of 5 May) were over 70 years old, three-quarters of whom lived in care facilities or received at-home care. ${ }^{5 \mathrm{i}}$

In addition, Savulescu and Cameron note that contact-tracing apps are unlikely to work when implemented voluntarily. It certainly seems that voluntary uptake will be insufficient to prevent a second lockdown. ${ }^{2}$ But as we are considering a mandatory selective lockdown here, perhaps a better point of comparison is a mandatory contact-tracing app. Such a possibility has been ruled out by many countries, but how might this compare to a selective isolation policy focused on the elderly? If both options provide an effective means of avoiding a general lockdown, which is to be preferred?

Lets look at the three arguments Savulescu and Cameron offer in support of selective isolation of the elderly. First, they suggest that selective isolation is an effective means to prevent another general lockdown (with all its associated economic and resulting health consequences). A contact-tracing app, as long as it is mandatory (or can otherwise achieve sufficiently high uptake) and centralised, also has the potential to slow the spread of COVID-19 enough to avoid a second lockdown. ${ }^{2}$

Second, they argue that the elderly themselves will benefit from selective isolation, because it will reduce their risk of death. As has been noted elsewhere, ${ }^{7}$ this paternalistic justification for enforced isolation should be viewed with extreme suspicion. It is also not clear if this restriction of liberty should be straightforwardly construed as a benefit. Prolonged isolation takes a significant toll on mental health, and Savulescu and Cameron are proposing that selective isolation be implemented 'until a vaccine or treatment arrives'1-a process that could take months or even years. It is well established in medical ethics that hard paternalistic justifications for restriction of liberty (or other conduct of comparable significance) are not justifiable in cases where the individual retains the ability to decide for himself what constitutes a benefit. ${ }^{8}$

The third justification is that selective isolation, when compared with a general lockdown, will lead to less overall loss of liberty. Although this involves

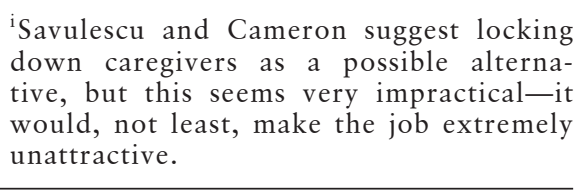


discriminating against a particular group, Savulescu and Cameron argue that such discrimination is justified when the burden is proportionate-the alternative, they argue, would be to lockdown everyone, including the elderly. Could this strategy also justify the selective isolation of other groups that show an increased propensity for severe side effects, like ethnic minorities, or men? Savulescu and Cameron contend that such measures are less justifiable, because the negative effects would be proportionally greater, and the proxy here is not as good. Elsewhere, they contend, 'if there were a better, more accurate proxy...then to continue to discriminate...would be unjust'. Age, they further claim, 'is the best available proxy' ${ }^{1}$ for the likelihood of serious illness (leading ultimately and cumulatively to an overburdened healthcare system, and thus the need for a second lockdown).

But, as Savulescu and Cameron note, only $18.4 \%$ of those over 80 who contract the disease must be hospitalised. The proportion of $70-79$ year olds is $16.6 \%$. $^{9}$ This proposed strategy involves locking down many people who will not pose 'indirect harm to others through consumption of limited resources'. ${ }^{1}$ So, age is not a great proxy, but is it the best available proxy? No-an effective contact-tracing app could achieve the same ultimate goal by targeting and quarantining those who are most likely to pose a direct risk of harm to others-those who have been exposed to the virus. This also has the advantage of not using group membership as the target factor, which carries clear risks of exacerbating existing group disadvantages or stigma, rather, it relies on the individual movements of every person. Of course, there will also be 'collateral damage' with this strategy, where false positives result in erroneous lockdowns. But in a centralised system, where the individuals who report symptoms can be followed up and tested, such erroneous lockdowns can be quickly reversed. Thus, individuals who do not pose a threat to others will only be quarantined for short periods of time, compared with the indefinite, perhaps years-long lockdown of the elderly.

The individual-centred nature of this strategy produces its own disadvantages. Under the centralised contact-tracing app that we are advocating, information is collected about whom individuals have been in contact with, which could be abused by authorities, and is vulnerable to hacking attacks. It is for this reason that Apple and Google have made it very difficult to develop a functioning app that stores any information in a centralised manner. ${ }^{10}$ This is certainly a serious problem, and it is an open question whether servers can be made sufficiently secure, and whether potential abuse can be mitigated with adequate legislation. However, due to the unpalatability of alternative options, including the extended isolation of certain segments of society, this mitigation strategy deserves more serious consideration. As Savulescu and Cameron note, no strategy is without its downsides.

Acknowledgements Many thanks to Dietmar Hübner and Donal Khosrowi for helpful discussion and comments.

Contributors Both authors contributed to the conception, drafting and revision of the manuscript.

Funding This research was funded in part by the Volkswagen Foundation within the project 'Bias and Discrimination in Big Data and Algorithmic Processing: Philosophical Assessments, Legal Dimensions, and Technical Solutions.'

\section{Competing interests None declared.}

Patient consent for publication Not required.

Provenance and peer review Not commissioned; internally peer reviewed.

This article is made freely available for use in accordance with BMJ's website terms and conditions for the duration of the covid-19 pandemic or until otherwise determined by BMJ. You may use, download and print the article for any lawful, non-commercial purpose (including text and data mining) provided that all copyright notices and trade marks are retained.

(C) Author(s) (or their employer(s)) 2020. No commercial re-use. See rights and permissions. Published by BMJ.

Check for updates
To cite White L, van Basshuysen P. J Med Ethics 2020;46:724-725

Received 6 July 2020

Accepted 8 July 2020

Published Online First 19 August 2020

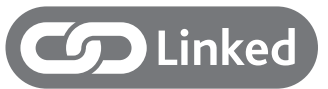

http://dx.doi.org/10.1136/medethics-2020-106336

J Med Ethics 2020;46:724-725.

doi:10.1136/medethics-2020-106680

ORCID iD

Lucie White http://orcid.org/0000-0001-8292-3789

\section{REFERENCES}

1 Savulescu J, Cameron J. Why lockdown of the elderly is not ageist and why levelling down equality is wrong. $J$ Med Ethics 2020;46:717-21.

2 Hinch R, Probert W, Nurtay A, et al. Effective configurations of a digital contact tracing APP: a report to NHSX. Available: https://045.medsci.ox.ac.uk/files/ files/report-effective-app-configurations.pdf [Accessed 2 Jul 2020]

3 Van Bunnik B, Morgan A, Bessel P, et al. Segmentation and shielding of the most vulnerable members of the population as elements of an exit strategy from COVID-19 lockdown. medRxiv.

4 Giritli Nygren K, Olofsson A. Managing the Covid-19 pandemic through individual responsibility: the consequences of a world risk society and enhanced ethopolitics. J Risk Res;6(4):1-5.

5 Swedish National Board of Health and Welfare,. Ny statistik om smittade och avlidna i covid-19 bland äldre [Swedish]. Available: https://www.socialstyrelsen. se/om-socialstyrelsen/pressrum/press/ny-statistikom-smittade-och-avlidna-i-covid-19-70-ar-och-aldre/ [Accessed 2 Jul 2020].

6 MIT technology review, MIT Covid tracing Tracker. Available: https://docs.google.com/spreadsheets/ d/1ATaIASO8KtZMx_zJREOOvFh0nmB-sAqJ1CjVRSCOw/ [Accessed 5 Jul 2020].

7 Miller F. Lockdown of the elderly is misguided policy. Journal of Medical Ethics Blog. Available: https:// blogs.bmj.com/medical-ethics/2020/06/23/lockdownof-the-elderly-is-misguided-policy/ [Accessed 2 July 2020].

8 Kopelman LM. On distinguishing justifiable from unjustifiable paternalism. Virtual Mentor 2004:6(2):72-4.

9 Verity R, Okell LC, Dorigatti I, et al. Estimates of the severity of coronavirus disease 2019: a model-based analysis. Lancet Infect Dis 2020;20(6):669-77.

10 Ilves I. Why are Google and apple dictating how European democracies fight the coronavirus? The Guardian, 2020. Available: https://www. theguardian.com/commentisfree/2020/jun/16/ google-apple-dictating-european-democraciescoronavirus 